\title{
Improving Building Energy System Performance by Continuous Commissioning
}

$$
\text { by }
$$

\author{
W. Dan Turner \\ Mingsheng Liu \\ David E. Claridge \\ Jeff S. Haberl
}

September 1996 


\section{Improving Building Energy System Performance by Continuous Commissioning}

The term Continuous Commissioning (CC) was first used by engineers at the Energy Systems Lab (ESL) at Texas A\&M University to describe an ongoing process which improves the operation of buildings using measured hourly energy use and environmental data. The first buildings to undergo a continuous commissioning process were in the Texas LoanSTAR program [Liu, et al, 1994, Claridge, et al, 1994]. These buildings had been retrofitted with various energy efficiency improvements, and measured hourly data were available to verify that the retrofits were performing as desired, and to analyze the overall building performance. The ESL engineers, using hourly data, site visits, and ESL-developed software [Liu and Claridge 1995], then worked with the facility engineers to fine-tune the building operation. These efforts were so successful that another 15 to $30 \%$ of the annual building energy cost was saved -- and these were in buildings that supposedly had all cost effective retrofits and operating improvements already implemented [Liu 1996].

\section{Continuous Commissioning in Retrofitted Buildings}

Table 1 gives examples of 10 buildings where the continuous commissioning process was used, and the annual savings which resulted. The energy savings were measured by using hourly data. The percentage savings were determined as the cost saving compared to the total annual building energy consumption (chilled water, hot water and electricity).

\footnotetext{
- LoanSTAR is an acronym for Loans to Save Taxes and Resources, a major public building retrofit program administered by the Texas State Energy Conservation Office, Tobin Harvey, Director. 
The measured percentage savings varied from $12 \%$ to $37 \%$ with an average savings of $25 \%$ [Liu, et al, 1994]. The measured annualized savings for the 10 buildings were $\$ 2,472,700 / y r$ with cumulative savings of $\$ 5,323,100$ through April 1996 .

Table 1. Measured Energy Savings due to Continuous Commissioning in Selected Buildings

\begin{tabular}{|l|c|c|c|c|c|}
\hline \multicolumn{1}{|c|}{ Building Type } & $\begin{array}{c}\text { Floor area } \\
\left(\mathrm{ft}^{2}\right)\end{array}$ & $\begin{array}{c}\text { Annualized } \\
\text { Savings } \\
(\$ / y r)\end{array}$ & $\begin{array}{c}\text { Savings } \\
(\%)\end{array}$ & $\begin{array}{c}\text { Cumulative Savings } \\
\text { Through April 1996 } \\
\$\end{array}$ & Months \\
\hline $\begin{array}{l}\text { Labs, classrooms \& } \\
\text { offices }\end{array}$ & 233,700 & $\$ 60,600$ & 12 & $\$ 126,000$ & 25 \\
\hline $\begin{array}{l}\text { Offices,classrooms } \\
\& \text { labs }\end{array}$ & 887,000 & $\$ 872,700$ & 24 & $\$ 1,527,000$ & 21 \\
\hline Medical research & 412,800 & $\$ 153,700$ & 20 & $\$ 373,800$ & 29 \\
\hline Medical research & 120,000 & $\$ 208,900$ & 30 & $\$ 504,700$ & 29 \\
\hline Hospital & 490,000 & $\$ 397,800$ & 31 & $\$ 961,000$ & 29 \\
\hline Hospital & 276,000 & $\$ 209,000$ & 37 & $\$ 505,000$ & 29 \\
\hline Surgical Center & 54,000 & $\$ 159,000$ & 37 & $\$ 411,000$ & 31 \\
\hline $\begin{array}{l}\text { Offices \& } \\
\text { Classrooms }\end{array}$ & 138,000 & $\$ 204,000$ & 32 & $\$ 579,000$ & 34 \\
\hline Library . & 67,000 & $\$ 37,000$ & 17 & $\$ 53,000$ & 17 \\
\hline Hospital & 373,000 & $\$ 170,000$ & 16 & $\$ 282,600$ & 20 \\
\hline Total & $3,051,500$ & $\$ 2,472,700$ & 25 & $\$ 5,323,100$ & \\
\hline
\end{tabular}

\section{Continuous Commissioning in New Construction}

The continuous commissioning process has also been extended to new construction at the Texas State Capitol Complex in Austin, Texas. One such building is the Capitol Extension building, which was completed in 1992 as an energy efficient building. It is located below grade next to the state Capitol and contains a covered atrium in the center of the building which houses legislative offices and hearing rooms. The first operational improvements were implemented in July 1995 with additional measures implemented through June 1996. During this period, a total of 15 operational improvements were implemented. The continuous commissioning has greatly improved indoor comfort 
conditions and reduced the total building energy cost by $\$ 100,300$ over 345 days (July 1, 1995 to June 11,1996$)$. The measured energy and cost savings are summarized in Table

2.

Table 2: Measured Energy Savings at the Capitol Extension Building (7/1/95 to 6/11/96)

\begin{tabular}{|l|l|l|l|}
\hline & $\begin{array}{l}\text { Energy Savings } \\
(\mathrm{MMBtu} \text { or } \mathrm{kWh})\end{array}$ & Cost Savings (\$) & $\begin{array}{l}\text { Ratio of } \\
\text { Savings/Cost }\end{array}$ \\
\hline Chilled Water & 12,030 & $\$ 39,100$ & $7 \%$ \\
\hline Hot Water & 7,980 & $\$ 30,640$ & $25 \%$ \\
\hline Electricity & $616,000 \mathrm{kWh}$ & $\$ 30,560$ & $53 \%$ \\
\hline Total & & $\$ 100,300$ & $20 \%$ \\
\hline Daily Average & & $\$ 290$ & $20 \%$ \\
\hline
\end{tabular}

\section{Continuous Commissioning Prior to Retrofits}

As a result of the Continuous Commissioning successes in the LoanSTAR

program, Texas A\&M University committed over one million dollars of its own money in 1995 to the Energy Systems Laboratory to instrument 70 of its largest buildings, the power plant, and the satellite thermal plants. As of July 1996 the power plant, thermal plants and approximately 30 buildings have been metered, with the remaining buildings to be metered by the end of 1996 . To date, several measures have been identified and implemented through the metering and the Continuous Commissioning process which will result in $\$ 750,000$ in annual savings. In addition, another $\$ 750,000$ of measures have been identified and are in process of implementation. Full implementation of these measures will provide the university with less than a one-year payback on its investment - 
- and there are still more than 40 buildings to be analyzed. Annual savings from the fully-implemented campus CC process are estimated to result in a $\$ 3$ million decrease in the campus energy bill!

Improved operation and control measures have been partially implemented in 10 buildings, where significant energy reduction has been observed. Figures $1 \& 2$ compare the measured chilled water and hot water consumption before and after continuous commissioning began at one of the buildings.

\section{Continuous Commissioning and Retrofits}

Both continuous commissioning and retrofits can reduce building energy consumption and improve the building comfort conditions. We have found that continuous commissioning can often provide as much or more savings than retrofits.

Figure 3 presents the annual energy costs in three facilities where extensive building energy retrofits were performed before continuous commissioning began [ESL, 1995]. The continuous commissioning process was at least as important as the energy retrofits in these facilities. 


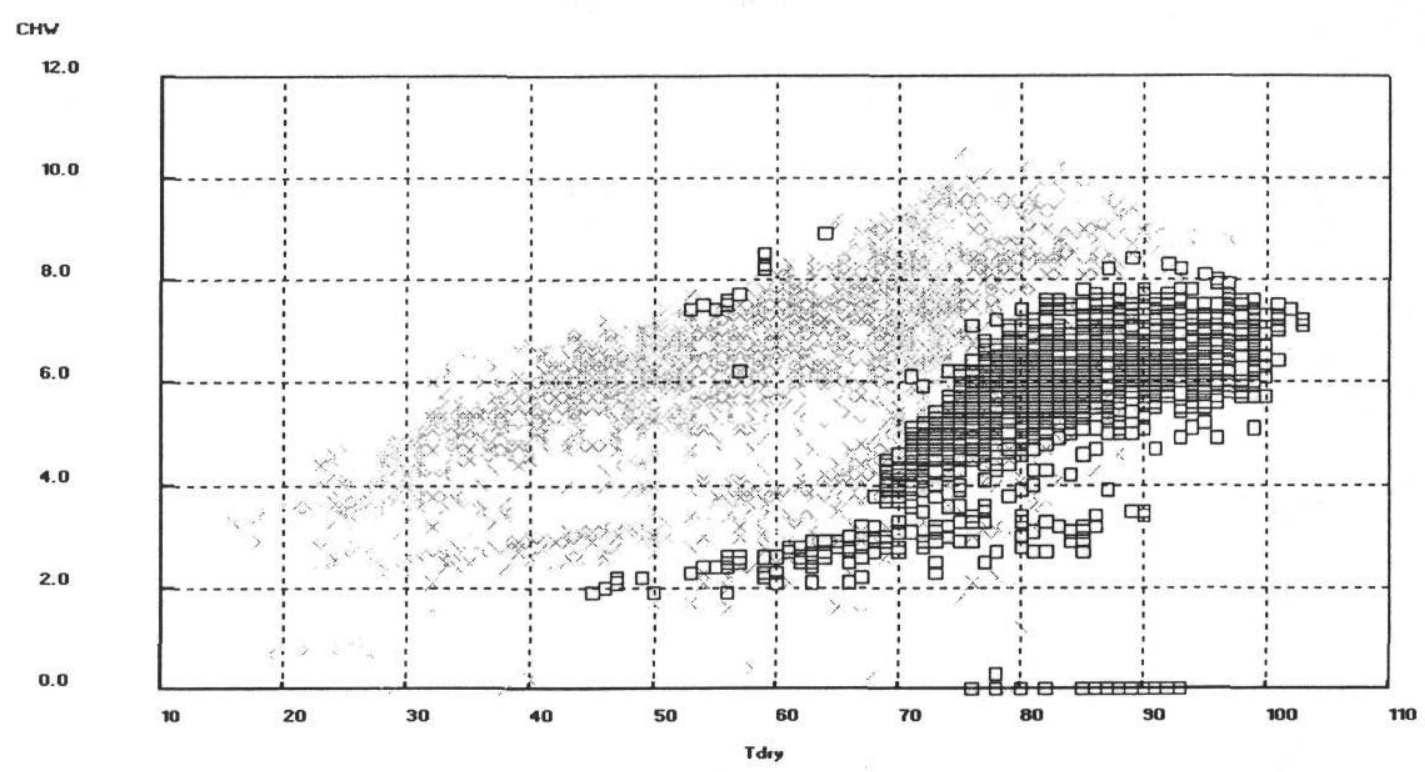

Figure 1: Comparison of Measured Chilled Water Consumption(MMBtu/hr) before (" $x$ ") and after (" $\square$ ") Continuous Commissioning in a Campus Building.



Figure 2: Comparison of Measured Hot Water Consumption (MMBtu/hr) before (" $x$ ") and after (" $\square$ ") Continuous Commissioning in a Campus Building. 


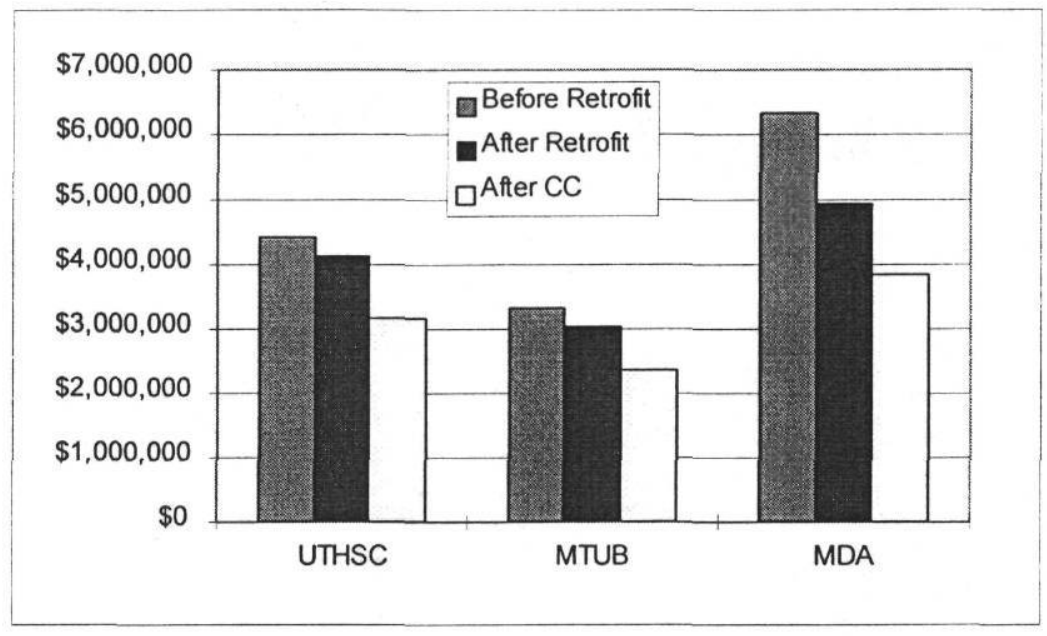

Figure 3: Energy Cost Before Retrofit, After Retrofit, and After Retrofit and CC.

There are several important reasons why Continuous Commissioning should be the first stage in an energy efficiency program. First, the evidence in study after study consistently shows that almost every building can be made more efficient, improving comfort as well as reducing energy consumption. In some instances a building's energy consumption can be reduced such that some retrofits will not be necessary (or cost effective). Another reason for Continuous Commissioning before retrofitting is that an improved energy consumption baseline can be established. A more accurate determination of actual savings from retrofits can be made if metered data and a good calibrated air-side building simulation model are available. From our experience at the Energy Systems Laboratory, there is little doubt that the Continuous Commissioning process is highly cost effective and is the preferred approach prior to a major retrofit program. 


\section{Continuous Commissioning, Comfort, and Indoor Air Quality}

It is not unusual to have indoor air quality and other comfort problems in existing buildings. Since the IAQ and comfort problems influence the productivity of office workers, continuous commissioning should resolve these problems before targeting energy savings, although it is hard to accurately evaluate the actual dollar savings from improved comfort.

In one building, the room relative humidity was as high as $70 \%$, and the room temperature varied from $68 \mathrm{~F}$ to $77 \mathrm{~F}$ from zone to zone. After commissioning, the building relative humidity was held below $55 \%$, and room temperatures were controlled within $1 \mathrm{~F}$ of the set point. During a second visit to the building, the building's occupants mentioned a noticeable improvement in the indoor conditions.

Do the improved indoor conditions come at the expense of increased energy consumption? Comparison of the energy bills before and after the continuous commissioning process showed a reduction in electricity use of about $20 \%$ [Liu, et al, 1996] following implementation.

\section{Continuous Commissioning to Outperform the Design Performance}

The continuous commissioning process is not just the usual cookbook of O\&M measures often used in the building recommissioning program. Innovative ideas can often be implemented in an existing facility which can result in significant energy savings. In 1994, we implemented hot duct air pressure control by using a hot air damper in an existing facility [Liu, et al, 1995]. Although the building was operated based on the 
specified design requirements, this new measure reduced the building total energy cost by $\$ 182,000 / y r$ or $16 \%$ of the total energy cost. This measure also eliminated the hot spots in the building.

\section{Typical Measures from the Continuous Commissioning Process}

The Continuous Commissioning process is not just the usual cookbook of O\&M measures often used in building recommissioning programs. Roughly $80 \%$ of the CC measures involve control systems changes and thus are highly effective in buildings containing an EMCS [Liu, et al, 1994, 1995, 1996]. Measures might include optimized hot and cold deck reset schedules, changes in outside air settings (after appropriate $\mathrm{CO}_{2}$ measurements are made), reduction in static duct pressures, variable speed drives, and in certain instances, changes in specific control strategies. To accomplish effective CC the ESL Engineers work closely with Physical Plant personnel to determine what will work and what changes the building personnel are comfortable in making. A team effort has to be established in the $\mathrm{CC}$ process, but the results documented herein clearly establish the success of the CC process.

If state buildings in Texas cost $\$ 300,000,00$ annually in utility bills statewide, then it is estimated that CC can conservatively save $\$ 30,000,000(10 \%)$ to $\$ 60,000,000(20 \%)$ of the state's annual utility bills. 


\section{References}

Claridge, David E., Mingsheng Liu, Yeqiao Zhu, Mustafa Abbas, Aamer Athar and Jeff Haberl, "Implementation of Continuous Commissioning in the Texas LoanSTAR Program: 'Can You Achieve 150\% of Estimated Retrofit Savings' Revisited," to be published in Proceedings of the 1996 ACEEE Summer Study.

Liu M., "Reducing Building Energy Consumption by Continuous Commissioning," Presentation to the Texas State Agency Energy Management Group, June, 1996.

Liu M., A. Athar, A. T. Reddy, D. E. Claridge, J. S. Haberl, \& Ed White, "Reducing Building Energy Costs Using Improved Operation Strategies for Constant Volume Air Handling System," ASHRAE Transactions, 1995.

Liu, Mingsheng, Y. Zhu, and D. E. Claridge, "An Advanced Economizer Controller for Dual Duct Air Handling Systems with a Case Application," Proceedings of 10th Symposium on Improving Building Systems in Hot and Humid Climates, Fort Worth, TX, May 1996.

Liu, Mingsheng, Y. Zhu, and D. E. Claridge, "Use of EMCS Recorded Data to Identify Potential Savings Due to Improved Operations \& Maintenance (O\&M)," Proceedings of 10th Symposium on Improving Building Systems in Hot and Humid Climates, Fort Worth, TX, May 1996.

Liu, Mingsheng, et al, "An O\&M Story in An Old Building," Proceedings of Fourth National Conference on Building Commissioning, St. Pete Beach, FL, April 29 to May 1, 1996.

Liu Mingsheng and David E. Claridge, "Operation Optimization Using Calibrated Simple HVAC System Models,” 1995 ASME/JSME/JSES International Solar Energy Conference, Maui, Hawaii.

Liu, Mingsheng, et al, "Reducing Building Energy Costs Using Optimized Operation Strategies for Constant Volume Air Handling Systems," Proceedings of Ninth Symposium on Improving Building Systems in Hot and Humid Climates, Arlington, TX, May, 1994.

Liu, Mingsheng, et al, "Identifying \& Implementing Improved Operation \& Maintenance (O\&M) Opportunities in LoanSTAR Buildings," Proceedings of 1994 ACEEE Summer Study, Pacific Grove, CA. August 28 - September 3, 1994. 